\title{
OPEN Author Correction: mPEG-PLA and PLA-PEG-PLA nanoparticles as new carriers for delivery of recombinant human Growth Hormone (rhGH)
}

Rohollah Ghasemi ${ }^{1}$, Mahdi Abdollahi $\mathbb{B}^{2}$, Elaheh Emamgholi Zadeh ${ }^{3}$, Khosrow Khodabakhshi ${ }^{4}$, Ali Badeli ${ }^{4}$, Hamed Bagheri ${ }^{5}$ \& Saman Hosseinkhani ${ }^{3}$

Correction to: Scientific Reports https://doi.org/10.1038/s41598-018-28092-8, published online 29 June 2018

In Figure $1 \mathrm{~b}$ the structural formula for PEG is incorrect. The correct Figure 1 appears below.

(a)<smiles>[Y]C(C)OCCC(C)(C)OCCC(C)(C)OCC(=O)C(C)OC</smiles>

(b)

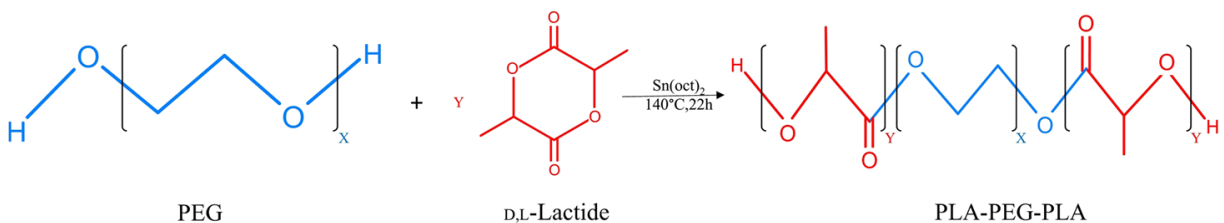

Figure 1. Schematic synthesis route of mPEG-PLA diblock and PLA-PEG-PLA triblock copolymers. (a) Diblock copolymers were prepared by ring opening polymerization (ROP) method using dl-lactide monomers, mPEG and stannous octoate as catalyst, so that dl-lactide monomers were grown from one end of mPEG. (b) Triblock copolymers were synthesized using dl-lactide monomers, PEG and stannous octoate, so that due to presence of hydroxyl groups at both ends of PEG, growth of PLA blocks occurred at both ends of PEG.

\footnotetext{
${ }^{1}$ Department of Nanobiotechnology, Faculty of Biological Sciences, Tarbiat Modares University, Tehran, 14115175, Iran. ${ }^{2}$ Polymer Engineering Department, Faculty of Chemical Engineering, Tarbiat Modares University, Tehran, 14115-114, Iran. ${ }^{3}$ Department of Biochemistry, Faculty of Biological Sciences, Tarbiat Modares University, Tehran, 14115-175, Iran. ${ }^{2}$ Processing Department, Iran Polymer and Petrochemical Institute, Tehran, 14965-115, Iran. ${ }^{5}$ Faculty of Interdisciplinary Science and Technology, Tarbiat Modares University, Tehran, 14115-336, Iran. Correspondence and requests for materials should be addressed to S.H. (email: saman_h@modares.ac.ir)
} 
(c) (i) Open Access This article is licensed under a Creative Commons Attribution 4.0 International License, which permits use, sharing, adaptation, distribution and reproduction in any medium or format, as long as you give appropriate credit to the original author(s) and the source, provide a link to the Creative Commons license, and indicate if changes were made. The images or other third party material in this article are included in the article's Creative Commons license, unless indicated otherwise in a credit line to the material. If material is not included in the article's Creative Commons license and your intended use is not permitted by statutory regulation or exceeds the permitted use, you will need to obtain permission directly from the copyright holder. To view a copy of this license, visit http://creativecommons.org/licenses/by/4.0/.

(C) The Author(s) 2019 